\title{
Family Before Self: An Understanding of Domestic Violence in India
}

\author{
S.Gayathri \\ Indian Institute of Technology, Madras
}

\begin{abstract}
The identity of an individual in Indian society has been constructed primarily based on the family one belonged to, regardless of one's status or background. Implied by this belief is that the individual is intertwined with the family for support, construction of value systems, faith, and development. The Indian family has an overarching influence on almost every action of an individual and this paper seeks to establish the link between crime and family through the concept of 'family violence'. The Indian society is inherently patriarchal, and a clear demarcation of gender roles have perpetrated every sphere. Owing to this, what may be regarded as a crime outside the family is overlooked as normal when it happens in a family. There has always been a general cultural reluctance to recognize family matters as a problem of significant consequence, with the lack of response from the legal system reinforcing the practice of understating family violence a crime. This paper seeks to understand the reasons behind the negligence of scholars to study family violence even though it comes under a variety of disciplines. The paper wishes to problematize the implementation of Constitutional law in the household, with an emphasis on India. If it is deemed appropriate, where does one draw the line between a 'family matter' and a criminal act, liable for punishment? This paper wishes to understand the circumstances under which the need for Domestic Violence Protection Act arose in the Indian Penal Code. The paper will also investigate the factors and policy interventions which engender the prejudice people have of gender roles and expectations.
\end{abstract}

Keywords: Crime; Domestic Violence Protection Act; Family; Gender; Violence 